\title{
CHAMP magnetic anomalies of the Antarctic crust
}

\author{
Hyung Rae Kim ${ }^{1}$, Luis R. Gaya-Pique ${ }^{2,3}$, Ralph R. B. von Frese ${ }^{4}$, Patrick T. Taylor ${ }^{5}$, and Jeong \\ Woo $\mathrm{Kim}^{6}$ \\ ${ }^{1}$ GEST/UMBC at Geodynamics, Code 921, GSFC/NASA, Greenbelt, MD 20771, USA, \\ ${ }^{2}$ Istituto Nazionale di Geofisica e Vulcanologia, Roma, V. Vigna Murata 00143 Rome, Italy, \\ ${ }^{3}$ Observatori de l'Ebre, 43520 Roquetes, Spain, \\ ${ }^{4}$ Dept. of Geol. Sci., The Ohio State Univ., Columbus, OH 43210, USA \\ ${ }^{5}$ Geodynamics Branch, NASA/GSFC, Greenbelt, MD 20771, USA, \\ ${ }^{6}$ Dept. Geoinfo. Eng., Sejong Univ., Seoul, Republic of Korea.
}

Summary: Regional magnetic signals of the crust are strongly masked by the core field and its secular variations components and hence difficult to isolate in the satellite measurements. In particular, the un-modeled effects of the strong auroral external fields and the complicated behavior of the core field near the geomagnetic poles conspire to greatly reduce the crustal magnetic signal-to-noise ratio in the polar regions relative to the rest of the Earth. We can, however, use spectral correlation theory to filter the static lithospheric and core field components from the dynamic external field effects. To help isolate regional lithospheric from core field components, the correlations between CHAMP magnetic anomalies and the pseudo magnetic effects inferred from gravity-derived crustal thickness variations can also be exploited. Employing these procedures, we processed the CHAMP magnetic observations for an improved magnetic anomaly map of the Antarctic crust. Relative to the much higher altitude Ørsted and noisier Magsat observations, the CHAMP magnetic anomalies at $400 \mathrm{~km}$ altitude reveal new details on the effects of intracrustal magnetic features and crustal thickness variations of the Antarctic.

Keywords : CHAMP, magnetic anomalies, Antarctica, crustal thickness.

\section{Introduction}

Satellite magnetic data from the POGO, Magsat, Ørsted and CHAMP missions play a critical role in understanding regional or global magnetic anomaly variations due to petrological variations of the crust and upper mantle, and crustal thickness and thermal perturbations (e.g., [1], [2]; [3], [4]). Data from satellite observations provide uniform magnetic coverage to within a few degrees of the poles [Champ data virtually covers all of the poles]. However, the relatively enhanced density of satellite data at the poles is definitely useful for polar geologic studies that generally lack coverage by conventional near-surface anomaly surveys due to the remoteness and harsh environmental conditions of the polar regions.

CHAMP magnetic observations offer significant advantages for Antarctic crustal studies over the data from NASA's Magsat mission. For example, the Magsat data collected only over a 6month period during austral summer when external field activity is strongest are highly contaminated by non-lithospheric noise in the Antarctic. The CHAMP satellite, by contrast, has been operating since July 2002 and collected with considerably greater accuracy a much larger quantity of relatively low-noise data over several austral winters. The improved CHAMP 
magnetic data offer significant opportunities for developing new insight on the features and development of the poorly understood south polar crust.

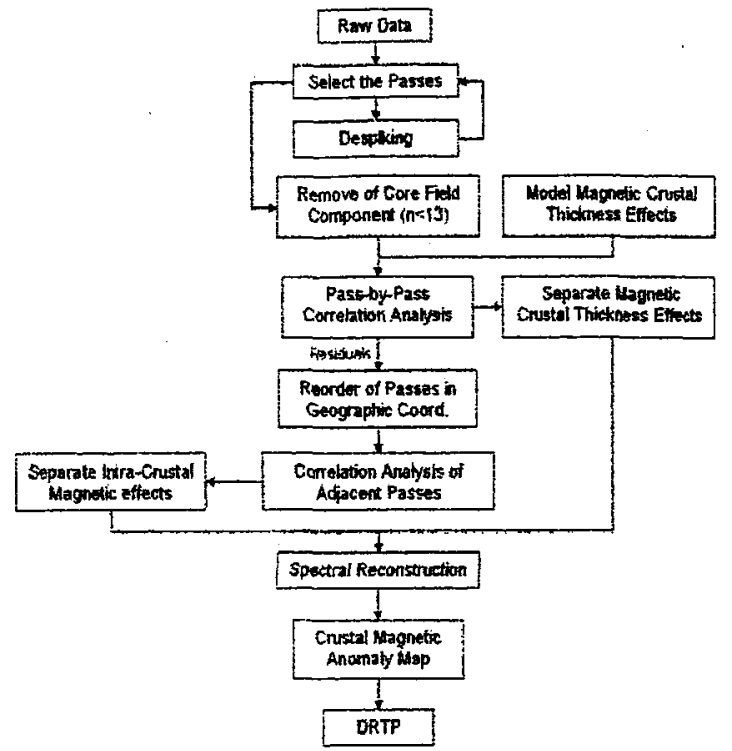

Fig.1. Flowchart for processing the CHAMP Antarctic magnetic data for crustal anomalies.

In general, the magnetic effects of crustal sources at satellite altitudes reflect both inductive and remanent components of magnetization. As crustal depth increases, however, remanent and thermal overprints are diminished while viscous magnetization is enhanced as temperature increases to within about $100-150^{\circ} \mathrm{C}$ of the Curie point of magnetite. The effects of viscous magnetization are in-phase with the induced component and may be particularly strongly expressed at sateilite altitudes.

Thermoremanently magnetized sources, on the other hand, are predominantly located in the upper crust. These sources produce relatively high frequency signals that are particularly strong at the near-surface, but considerably attenuated at satellite altitudes. Exceptions here are the regional signals from extensive areas of oceanic crust that were produced during a long normal polarity interval in the Cretaceous. The effects of the oceanic Cretaceous Quiet Zones are commonly observed at satellite altitudes (e.g., [5]).

Satellite anomalies from typical global spherical harmonic models, however, can be problematic for polar lithospheric studies because the strong and complex effects from the auroral external fields are only marginally accounted for in the anomaly estimates. Hence, in this study, we use advanced spectral correlation theory to process CHAMP magnetic observations south of $60^{\circ} \mathrm{S}$ for anomalies with maximum crustal signal-to-noise ratios, where the noise components are composed of external field and other dynamic non-crustal effects.

\section{Antarctic Crustal Magnetic Anomalies From CHAMP Observations}

Our processing of the south polar CHAMP magnetic observations follows the flow chart in Figure 1 ([6]; [7]). We develop a comprehensive Antarctic magnetic crustal anomaly map from the CHAMP observations that includes the regional crustal thickness effects as well as the higher frequency intracrustal effects (e.g., [6] [7]).

Figure 2.A shows the crustal thickness model of the Antarctic produced by [8] using the spectral correlation analysis of free-air and computed terrain gravity effects at satellite altitude. Figure 2.C gives the related total magnetic anomalies at $400 \mathrm{~km}$ that we modeled by GaussLegendre quadrature integration using the core field attributes shown in Figure 1.B. To more directly appreciate the relationships between the crustal thickness variations and the satellite altitude magnetic anomalies, reduced the total field anomalies (Fig. 2.C) differentially to the radial pole in Figure 2.D. The differentially reduced-to-pole (DRTP) anomalies clearly reveal an enhanced image of the continent-ocean edge effects for the Antarctic. 

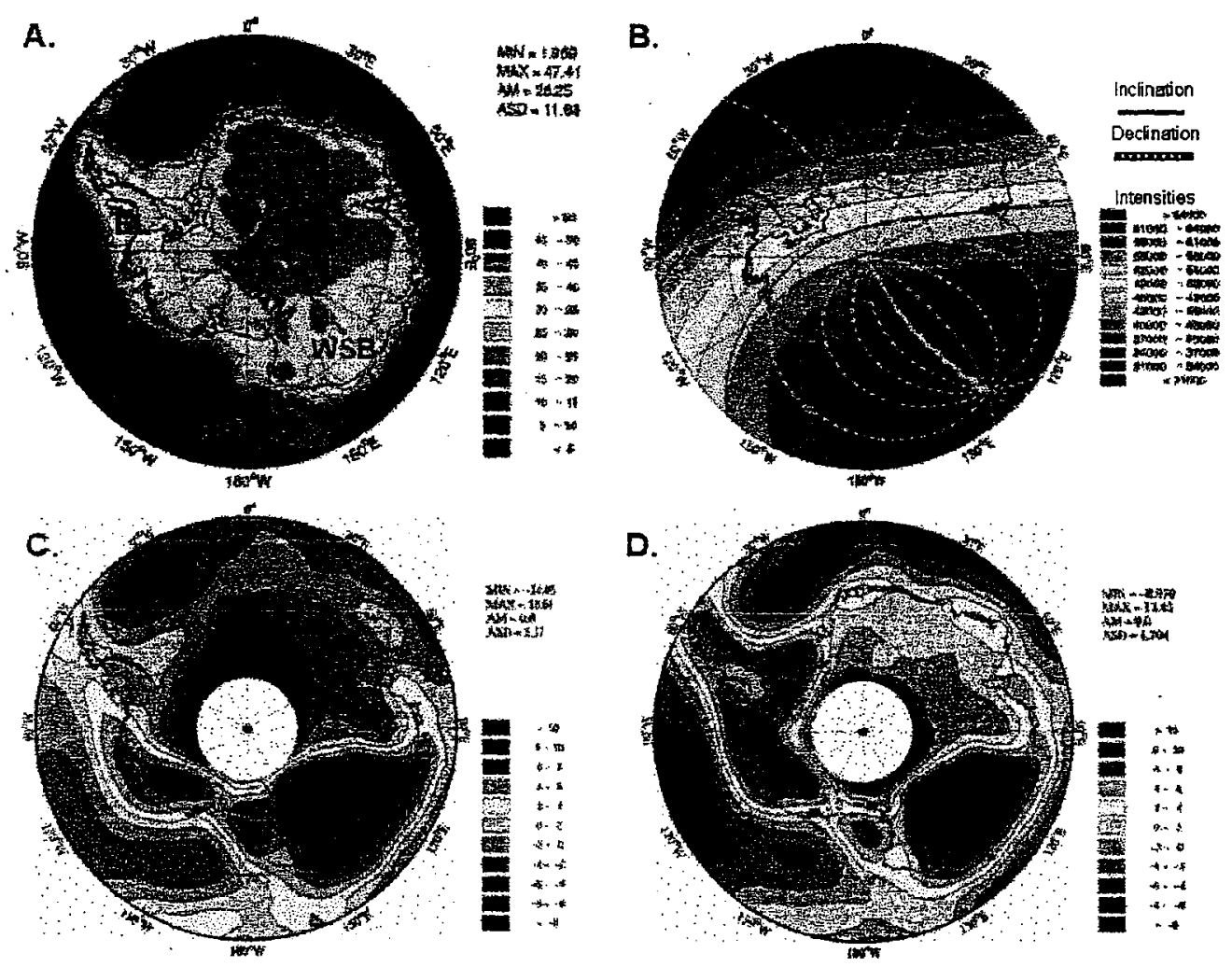

Fig. 2. A) Antarctic crustal thickness variations from gravity and topography data (von Frese et al., 1999). Annotations include the maximum (MAX) and minimum (MIN) amplitude values, the amplitude mean (AM) and amplitude standard deviation (ASD). B) Core field attributes from the CHAMP spherical harmonic model [9]. The magnetic effects (in $\mathrm{nT}$ ) of the crustal thickness variations are evaluated as total field and differently reduced-to-pole (DRTP) anomalies at $400 \mathrm{~km}$ in maps (C) and (D), respectively.

To facilitate extracting the possible effects due to the thickness variations of the Antarctic crust from the CHAMP data on a track-by-track basis, the magnetic effects in Figure 2.C were modeled using spherical cap harmonic (SCH) analysis (e.g., [10]). The maximum spatial index was chosen equal to 30 , being the model defined by a total of 481 coefficients on a 30 degrees half angle cap.

As shown in the processing flowchart of Figure 1, we first removed estimates of the core field from the CHAMP observations. The residuals were then spectrally correlated with the predictions from SCH model of the crustal thickness effects along each satellite track. Signals in the CHAMP anomaly residuals that were positively correlated with the $\mathrm{SCH}$ predictions were extracted as shown in Figure 2.A.

The remaining higher frequency satellite measurements were next sorted into orbital pairs of nearest-neighbor tracks to extract the static, correlated features that presumably reflect the effects of additional crustal sources ([11]; [12]). Negatively or null correlated signals between tracks separated by distances that are small clearly cannot be related to features of the crust, but rather must be related to the dynamic effects of external fields and other non-crustal noise.

Figure 3.C gives the estimates resulting from the track-by-track spectral correlation analysis that we take to reflect mostly the intracrustal magnetization variations. The magnetic effects from crustal thickness variations and the intracrustal magnetization variations were then added together and plotted in Figure 3.E. The DRTP anomalies for the respective maps are also presented in Figure 3.B, 3.D and 3.F. 

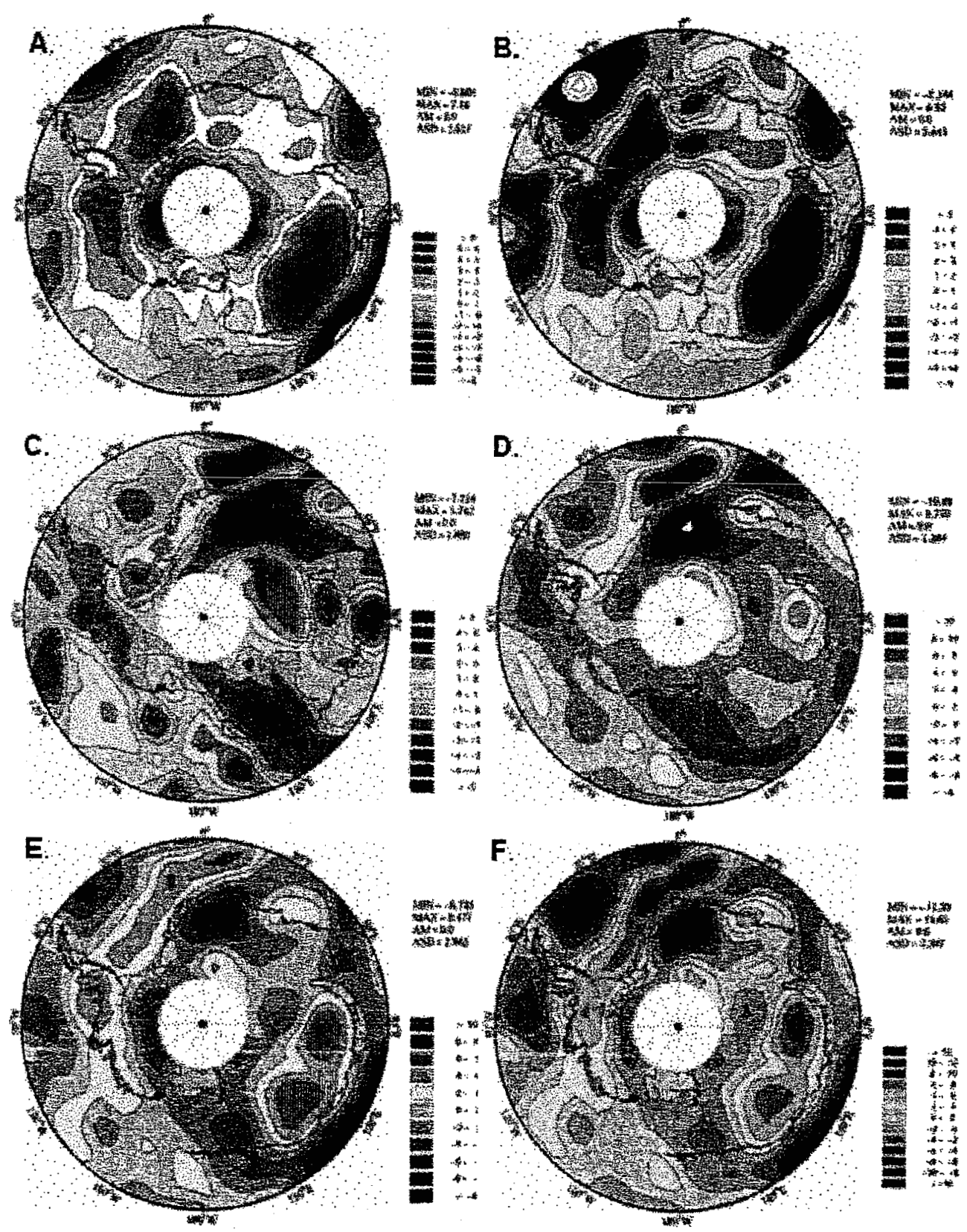

Fig. 3. CHAMP magnetic anomalies at $450 \mathrm{~km}$ altitude include A) total field and B) DRTP crustal thickness magnetic effects at contour interval $\mathrm{CI}=1 \mathrm{nT} ; \mathrm{C}$ ) total field and D) DRTP magnetic anomalies at $\mathrm{CI}=1 \mathrm{nT}$ and $2 \mathrm{nT}$, respectively; and E) total field and F) DRTP (F) comprehensive crustal magnetic anomalies at $\mathrm{CI}=2 \mathrm{nT}$.

\section{Discussion and Conclusion}

Figures 3.A and B show the resulting CHAMP magnetic anomaly map that can reflect the Antarctic continent-ocean edge effects. The dominant portion of the large anomalies over Wilkes Subglacial Basin (WSB in Figure 2.A) appear to reflect the integrated edge effects of the underlying thinned crust (Fig. 2.A) that involves the continent-ocean boundary and thicker crust underlying the Transantarctic Mountains (TAM) on west and the Gamburtsev Mountains (GM) to 
the east. The intractustal anomalies over this area are comparatively weakly expressed in Figures 3.C and D.

A prominent elongated positive intracrustal anomaly overlies Maude Rise (MR) that reflects the remanent magnetization effects of this Cretaceous Quiet Zone (e.g., [13] [14]). This long linear positive anomaly extends from Maud Rise along the eastern margin of the Weddell Sea Embayment (WSE) to Ellsworth Land (EL) where a series of microplates are assembled (e.g., [15]). This linear anomaly is a relatively robust feature because it is also seen in degree $15-90$ components of the global spherical harmonic map of the CHAMP magnetic data produced by [16]. Further insight on the crustal significance of this feature can result from joint modeling of both satellite and near-surface magnetic observations (e.g., [8] [14]).

We are currently extending this study to include the regional remanent magnetization effects from the Cretaceous Quiet Zones about Antarctica (e.g., [4]). We are also investigating the joint use of satellite and near-surface magnetic anomalies to constrain Curie isotherm estimates and related heat flow variations of the Antarctic crust that may affect the dynamics of the overlying ice sheets. Our efforts to understand the magnetic properties and evolution of the lithosphere will be significantly enhanced by the new high-precision and high-resolution measurements of the magnetic field that the proposed SWARM satellite project will obtain from four satellites in two different polar orbits.

\section{References}

1. von Frese, R R B., Hinze, W J and Braile, L W, 1982. Regional North American gravity and magnetic anomaly correlations, Geophys. J. R. Astron. Soc., 69, 745-761.

2. von Frese, R R B, Kim, H R, Tan L, Kim, J W, Taylor, P T, Purucker, M E, Alsdorf, D E and Anderson, A J, 1999. Satellite magnetic anomalies of the Antarctic crust, Annali di Geofisica, 42, 293-307.

3. Mayhew, M A, Johnson, B D and Wasilewski, P J, 1985. A review of problems and progress in studies of satellite magnetic anomalies, J. Geophys. Res., 90, 2511-2542.

4. Purucker, M E, von Frese R R B and Taylor, P T, 1999. Mapping and interpretation of satellite magnetic anomalies from POGO data over Antarctic region, Annali di Geofisica, 42, 215-228.

5. LeBrecque, $J \mathrm{~L}$ and Raymond, $\mathrm{CA}$, 1982. Seafloor spreading anomalies in the Magsat field of the North Atlantic, J. Geophys. Res., 9, 250-253.

6. von Frese, R R B and Kim, H R 2003, Satellite magnetic anomalies for lithospheric exploration, Proceedings of OIST-4,115-118

7. Kim, H R, von Frese, R R B, Kim, J W, Taylor, P T, and Neubert, T, 2002, Ørsted verifies regional magnetic anomalies of the Antarctic lithosphere," Geophys. Res. Lett, 29, 8002-8005.

8. von Frese, R R B, Tan, L, Kim, J W, Bentley, C R, 1999. Antarctic crustal modeling from the spectral correlation of free-air gravity anomalies with the terrain, J. Geophys. Res., 104, 25275-25297.

9. Olsen, N, Sabaka, T and Tøffner-Clausen, L, 2000. Determination of the IGRF 2000, Earth, Planets and Space, 52, 1175-1182.

10. Haines G V, 1985Spherical cap harmonic analysis, J. Geophys. Res., 90, 2583-2591. 
11. Alsdorf, D E, von Frese, R R B, Arkani-hamed, J and Noltimier, H C, 1994. Separation of lithospheric, external, and core components of the south polar geomagnetic field at satellite altitudes, $J$. Geophys. Res., 99, 4655-4667.

12. von Frese, R R B, Jones, M B, Kim, J W and Kim, J-H, 1997, Analysis of anomaly correlations, Geophysics, 62, 342-351.

13. Fullerton, L G, Frey, H V, Roark, J H and Thomas, H H, 1994, Contributions of Cretaceous Quiet Zone natural remanent magnetization to Magsat anomalies in the Southwest Indian Ocean, J. Geophys. Res., 99, 11923-11936.

14. Kim, H R, 2002, Antarctic lithospheric anomalies from Orsted satellite and near-surface magnetic observations (unpublish.), Ph. D. thesis, The Ohio State Univ., Columbus, Ohio.

15. Danziel, I W D and Elliot, D H, 1982, West Antarctica: Problem child of Gondwanaland, Tectonics, 1, 3-19.

16. Maus, S. Rother, M, Luehr, H, Balasis, G, Olsen, N \& Kuvshinov, 2003, (they are preparing for a manuscript presently) http://www.gfz-potsdam.de/pb2/pb23/SatMag/litmod3.html 